\section{Cahiers de Narratologie}

Analyse et théorie narratives

$12 \mid 2005$

Récit et éthique

\title{
Rabatel, Alain, Argumenter en racontant, Bruxelles, De Boeck, 2004, 133 p.
}

\section{(2) OpenEdition}

Journals

Édition électronique

URL : http://journals.openedition.org/narratologie/31

DOI : 10.4000/narratologie.31

ISSN : 1765-307X

Éditeur

LIRCES

Référence électronique

"Rabatel, Alain, Argumenter en racontant, Bruxelles, De Boeck, 2004, 133 p. », Cahiers de Narratologie

[En ligne], 12 | 2005, mis en ligne le 21 juillet 2005, consulté le 21 avril 2019. URL : http://

journals.openedition.org/narratologie/31; DOI : 10.4000/narratologie.31

Ce document a été généré automatiquement le 21 avril 2019

Article L.111-1 du Code de la propriété intellectuelle. 


\section{Rabatel, Alain, Argumenter en racontant, Bruxelles, De Boeck, 2004,}

\section{$133 p$.}

1 Alain Rabatel est professeur de Sciences du Langage à l'IUFM de Lyon. Ses nombreux travaux portent sur l'approche énonciative des textes littéraires et des interactions orales. Cet ouvrage, publié par l'éditeur belge De Boeck, dans la collection «Savoirs pratiques ", est destiné aux formateurs ainsi qu'aux étudiants en lettres. Cependant, il s'adresse aussi à ceux qui s'intéressent à l'analyse et à la théorie du récit.

2 Fondamentalement, ce livre repose sur les relations qu'entretient la narration avec l'argumentation. Partant du constat selon lequel « l'argumentation est loin de se limiter à des raisonnements "froids", qui doivent bannir la subjectivité du locuteur et de ses passions ", l'auteur propose d'examiner les diverses formes d'argumentation en contexte narratif. L'accent est ainsi plutôt mis «sur la construction textuelle du pathos (en objectivant des effets à produire sur l'interlocuteur) et de l'ethos (à travers le rôle argumentatif/persuasif de la construction de l'image de soi dans le discours) ».

3 En amont de cette approche, Alain Rabatel rappelle les hypothèses des Sciences Humaines sur l'émergence de la fonction narrative chez l'homme et son rôle social. Enfin, la dernière partie de l'introduction justifie l'approche didactique adoptée dans l'ouvrage. Le cœur du livre est constitué de sept étapes : (1) le point de vue représenté, (2) le point de vue raconté, (3) le point de vue asserté (4) la valeur argumentative des chaînes anaphoriques dans le cadre de l'effet point de vue, (5) les valeurs persuasives des connecteurs et marqueurs temporels en contexte narratif, (6) la valeur persuasive de l'ethos dans le point de vue asserté, (7) la fonction persuasive de la stéréotypie ; fonction argumentative de la stéréotypie mise à distance. Les chapitres proposent des exercices de récriture qui permettent aux élèves de comprendre ainsi les mécanismes mis en œuvre dans le texte. Ils contiennent par ailleurs des fiches résumant les approches théoriques sur les points concernés. 